\title{
HISTOLOGICAL STUDY ON THE PROTECTIVE EFFECTS OF TAMARIND SEED EXTRACT ON COBRA VENOM IN MICE
}

\author{
IMAD M AL-ANI ${ }^{1}$, SORAYA ISMAIL ${ }^{1}$, KHIN M MAUNG ${ }^{1}$, PAKEER OOTHUMAN ${ }^{1}$, \\ SINAN MOHAMMED ABDULLAH AL-MAHMOOD ${ }^{2 *}$
}

\begin{abstract}
${ }^{1}$ Department of Basic Medical Sciences, Kulliyyah of Medicine, International Islamic University Malaysia, Kuantan, Malaysia. ${ }^{2}$ Department of Basic Medical Sciences, Kulliyyah of Nursing, International Islamic University Malaysia, Level 2, Jalan Hospital Campus, 25710 Kuantan, Pahang Darul Makmur, Malaysia. Email: Sinan.almawla@gmail.com
\end{abstract}

Received: 17 May 2017, Revised and Accepted: 04 July 2017

\begin{abstract}
Objective: Tamarind (Tamarindus indica) has been used as a medical plant for treating many human and animal diseases and widely used as a traditional herbal medicine for the treatment of snake bites. The objective of the study is to investigate whether tamarind seed extract (TSE) has neutralization activity on an adverse histological reaction against venoms of the King Cobra.

Methods: A total of 20 healthy mature male mice were randomly divided into 4 groups with 5 mice in each. The control group was injected with 1 ml of normal saline. The second group was injected subcutaneously with a single dose of $24.96 \mu \mathrm{g} / 20 \mathrm{~g}$ King Cobra venom (KCV) solution. The third group was injected with the same dose of KCV solution and $10 \mathrm{mg} / 20 \mathrm{~g}$ of TSE. The fourth group was injected with the same dose of KCV solution and $15 \mathrm{mg} / 20 \mathrm{~g}$ TSE solution. The animals were sacrificed after $24 \mathrm{hrs}$ of injection of the solution. Fragments of muscle, kidney, and liver were fixed in $10 \%$ neutral buffered formalin and processed for light microscopical studies.
\end{abstract}

Results: The result showed that TSE reduced the histopathological changes induced by the KCV in the muscles, livers, and kidneys, and the improvement was proportional to the applied dose of the TSE indicating that TSE prevents adverse histological changes in the muscle, liver, and kidney.

Conclusion: The present study demonstrated that TSE reduced the histopathological changes in the muscle, liver, and kidney induced by KCV in mice.

Keywords: Histological effect, Tamarind seed, Cobra venom.

(C) 2017 The Authors. Published by Innovare Academic Sciences Pvt Ltd. This is an open access article under the CC BY license (http://creativecommons. org/licenses/by/4. 0/) DOI: http://dx.doi.org/10.22159/ajpcr.2017.v10i10.20040

\section{INTRODUCTION}

Snakebite constitutes a highly relevant, public health problem causing a significant global morbidity and mortality, affecting primarily poor populations in the rural settings of Africa, Asia, Latin America, and parts of Oceania [1]. The true number of deaths due to snakebite has been documented as 5,400,000 bites with 2,50,000 envenomation and 1,25,000 deaths annually worldwide among them India reporting higher mortality rates [2]. Many snake venoms induce histopathological changes in the victim at the site of bite or the nearby muscle tissues. Such changes include disorganization of the bundles or the complete degeneration of muscle fibers $[3,4]$. Snake venom also induces degeneration in the liver tissue, causing inflammatory cellular infiltrations around the hepatic vein, sinusoidal congestion, hepatocellular degeneration, and prominent Kupffer cells [5]. In the kidney, snake venom induces severe morphologic changes in the renal glomeruli developed into complete lysis in renal corpuscles with ruptured Bowman's capsules, intertubular medullary hemorrhage, and acute tubular necrosis $[6,7]$.

The King Cobra (Ophiophagus hannah) is an Elapid, is one of the largest deadliest snakes, and is found predominantly throughout tropical Asia, ranging from India to Vietnam and southern China and from the Philippines southward to Malaysia and Indonesia [8]. The venom of King Cobra is able to induce myotoxicity, cardiotoxicity, and antiplatelet effects [9].

The immunotherapy is the only treatment available, but it has side effects like serum illness, pyrogen reactions moreover the non-availability and storing problems have lead the researchers to look for other sources to treat snake bite effects (2). It has been reported that various medicinal plants species such as Hibiscus aethiopicus L. [10], Sabah Snake Grass [11], and Andrographis paniculata [12] can effectively reduce or neutralize all the fourteen toxic cobra venom proteins and used against snake envenomation in folkloric medicine. Tamarind plant (Tamarindus indica), aside from its use in cooking, is also employed for medicinal purposes and widely used as traditional herbal medicine. The medical values of tamarind involve anthelminthic, anti-inflammatory, antifungal, antidiuretic, antibacterial, and have central analgesic activity $[13,14]$ and used for the treatment of snake bite in rural areas of many Asian countries [15]. Therefore, the purpose of the present investigation is to determine whether the Tamarind plant seed extract would alter the adverse histopathological changes induced by King Cobra Venom (KCV) in the muscles, liver, and the kidneys of experimentally envenomed mice.

\section{METHODS}

Venom

KCV was kindly donated by the herbarium of the Mini-Zoo of Kuantan, Pahang, Malaysia. Venom collected was dried in desiccators at $4^{\circ} \mathrm{C} . \mathrm{KCV}$ was dissolved in the normal saline solution to get a $24.96 \mu \mathrm{g} / 100 \mu \mathrm{l}$ solution for further studies.

\section{Plant seeds}

Tamarind plant fruit that is used for cooking purpose was bought from markets of Kuantan, Malaysia, and dry seed was crushed in kitchen blender to separate seed coat and cotyledon. Seed coat undergoes Soxhlet extraction with $95 \%$ ethanol, and the solvent was removed by evaporation at $65^{\circ} \mathrm{C}$. Dried tamarind seed extract (TSE) powder was 
dissolved in the normal saline solution to get different concentration for further studies.

\section{Animals}

20 healthy mature male mice (ICR strain) $(20 \pm 2 \mathrm{~g}$ body weight) were kept at a temperature of about $24+2^{\circ} \mathrm{C}$ and exposed to $12 \mathrm{hrs} /$ day light program. The animal experiment was approved by the Animal Care and Use Committee of IIUM (IIUM/IACUC-2017/5). All animals were treated according to the Standards and Regulations for the Care and Use of Laboratory Animals of the National Institutes of the Health and according to the guidelines of IIUM animal ethics.

\section{Experimental design}

The animals were randomly divided into four groups with 5 mice in each. The first control (C) group was injected with $1 \mathrm{ml}$ of normal saline. The second group (V) was injected subcutaneously under the dorsal skin with a single dose of $24.96 \mu \mathrm{g} / 20 \mathrm{~g} \mathrm{KCV}$ solution. The third group (TV1) was injected with a single dose of $24.96 \mu \mathrm{g} / 20 \mathrm{~g} \mathrm{KCV}$ solution, and after half an hour, TSE solution containing $10 \mathrm{mg} / 20 \mathrm{~g}$ was injected, near the site where the venom was injected. The fourth group (TV2) was injected with a single dose of $24.96 \mu \mathrm{g} / 20 \mathrm{~g} \mathrm{KCV}$ solution, and after half an hour, TSE solution containing $15 \mathrm{mg} / 20 \mathrm{~g}$ was injected, near the site where the venom was injected.

The animals were sacrificed after $24 \mathrm{hrs}$ of injection of the solutions, and thigh muscles were extracted from its anatomical compartment. The abdominal cavity was opened, and the kidneys and liver were removed. Fragments of muscles, kidneys, and livers were fixed in $10 \%$ neutral buffered formalin, dehydrated in graded series of ethanol, cleared in xylene, impregnated and embedded in paraffin wax. Paraffin sections of $5 \mu \mathrm{m}$ thick were stained with Hematoxylin and Eosin.

\section{RESULTS}

\section{The skeletal muscles}

The histology of skeletal muscle of Group C exhibited normal size and organization, the muscle fibers with well-defined cross striation, and peripherally located nuclei (Figs. 1a and b). Mice of Group V treated with KCV solution showed severe degeneration changes in the muscle fibers, disorganization of the bundles with myonecrosis in the muscle fibers, and perivascular mononuclear infiltration. The disorganized muscle fibers had large and rounded; they lost their cross striation, and the sarcoplasm was slightly stained, blood vessels were congested and invaded by inflammatory cells (Fig. 1c and d). Examination of the skeletal muscles fiber of group TV1 obtained after $24 \mathrm{hrs}$ from envenoming with KCV and treated with the low dose of tamarind extract revealed a reduction of muscle fibers necrosis; however, few muscle fibers still showing myonecrosis, blood vessels were congested with aggregation of inflammatory cells (Fig. 1e and f). Skeletal muscles fiber mice from group TV2 envenoming with KCV and treated with high dose of TSE exhibited normal striation of the skeletal muscle fibers with the disappearance of all the histopathological changes (Fig. $1 \mathrm{~g}$ and $\mathrm{h}$ ).

\section{The liver}

Histological examination of liver sections from the control group showed normal hepatic architecture with distinct hepatocytes, sinusoidal spaces, and a central vein. The hepatocytes had a normal polygonal appearance with eosinophilic cytoplasm and a large spherical nucleus with a prominent nucleolus, some hepatocytes have two nuclei. The regular hepatocytes arranged in hepatic cords running radially from the central vein with blood sinusoids arranged in between these cords with the fine arrangement of Kupffer cells (Fig. 2a and b). The most pronounced histopathological abnormalities observed in rats of Group V treated with KCV solution showed the distorted liver architecture, degenerative changes in most of the hepatic lobules, the hepatocytes were enlarged with light and foamy cytoplasm filled with numerous vacuole-like spaces and apoptotic cell death. There was centrilobular coagulative necrosis characterized by loss of cellular detail, with severe congestion and dilatation in the central veins, sinusoidal dilatation, and prominent Kupffer cells. Mononuclear cellular infiltration was observed between

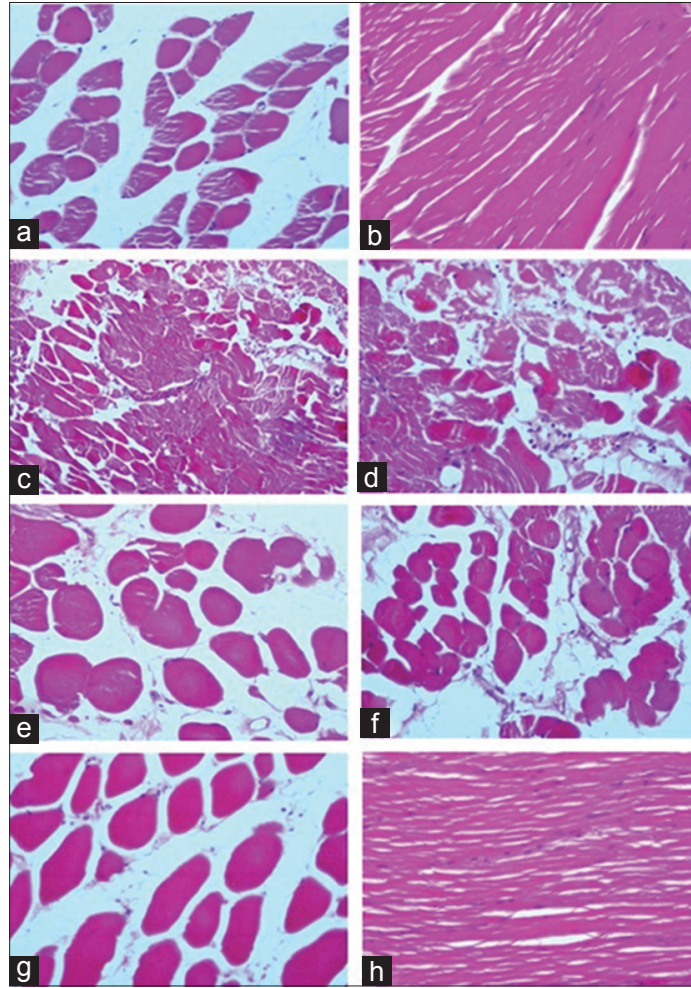

Fig. 1: Photographs of muscle tissue of a control mouse (a and b) showing the normal characteristics, ( $c$ and d) Group $V$ is showing myonecrosis in the muscle fibers and disorganization of muscle fibers, congested blood vessels, and perivascular mononuclear infiltration, (e and $f$ ) group TV1 showing reduction of muscle fibers necrosis with aggregation of inflammatory cells, ( $g$ and $h$ ) group TV2 showing disappearance of histopathological changes,

presence of regenerating fibers, and reappearance of cross striation in longitudinal section. $\mathrm{H}$ and $\mathrm{E}$. Original magnification; "a, b, d, e, f, $\mathrm{g} \times 40$ " “c, h $\times 20$ "

hepatocytes and around the central veins (Fig. 2c and d). Tamarind extract in combination with KCV (group TV1) caused a reduction of toxic effects of the venom, as indicated by mild degeneration and mild necrosis of hepatocytes, minimal vacuolization of hepatocytes, decrease in the sinusoidal dilation, and slight congestion of blood in the central vein and the blood sinusoids (Fig. 2e and f).

Treatment envenomed rats by KCV with a higher dose of TSE group improved the hepatic damage induced by KCV and resulted in remarkable histological regeneration compared to those of the low-dose group. The recovery is indicated by absence of hemorrhage and mononuclear cellular infiltration around the central vein; rearrangement of hepatic cords with increase normal-shaped hepatocytes of homogeneous cytoplasm and centrally located nuclei, the hepatic cords are separated by normal sinusoids, containing prominent Kupffer cells revealing normal architecture of the liver (Fig. 2g and h).

\section{The kidney}

Microscopic evaluation of renal cortex from the control group showed the normal histological features of the renal corpuscles and tubules; the corpuscle is formed of the glomerulus surrounded by Bowman's capsule. The proximal convoluted tubules (PCT) lined with cuboidal cells possessing intact brush border, the distal convoluted tubules show considerably low cuboidal to flatten shape epithelial cells and have a relatively regular distinct lumen (Fig. 3a and b). Examination of the renal cortex from KCV group revealed severe damage in renal tissues when compared to the non-treated control group; there were apparently shrunken glomeruli with increased density of the mesangial matrix and dilatation of Bowman capsule; thus, wide spaces appeared between Bowman's capsule and 

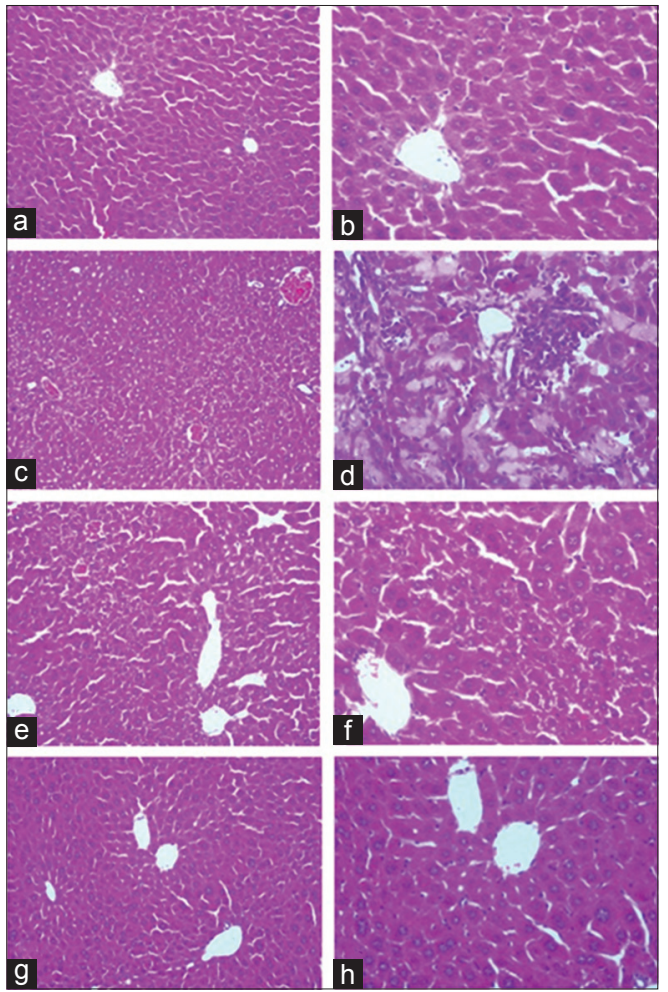

Fig. 2: Photographs of liver tissue of a control mouse (a and $b$ ) showing normal structural appearance of the liver, ( $c$ and d) Group $\mathrm{V}$ is showing distorted liver architecture, (e and $f$ ); group TV1 showing mild degeneration of hepatocytes and minimal vacuolization of hepatocytes. ( $g$ and $h$ ) group TV2 showing remarkable histological regeneration of the hepatocytes. $\mathrm{H}$ and E. Original magnification; " $\mathrm{a}, \mathrm{c}, \mathrm{e}, \mathrm{g} \times \mathbf{2 0}$ " " $\mathrm{b}, \mathrm{d}, \mathrm{f}, \mathrm{h} \times \mathbf{4 0}$ "

glomeruli. The renal tubules also showed degenerative changes and lost their characteristic appearance. The PCT showed dilatation, wide lumen with the loss of brush border; there was acute tubular necrosis, and shedding of epithelial lining and the lumen of most of the tubules were filled with degenerated and desquamated epithelial cells' debris and casts (Fig. 3c and d). The concomitant administration of tamarind extract and KCV group did not improve completely the lesions induced by the KCV; mild degenerative changes were observed, some glomeruli were shrunken, the epithelium of some renal tubular was still necrotic, and the dilated lumens contain cell debris (Fig. 3e and f). Furthermore, mild hyperemia in the cortical vessels and interstitial edema were present. Conversely, treatment envenomed rats with a higher dose of TSE group TV2 showed reduction to some extent, the intensity of the lesions induced by the KCV group. The cortical tissues showed the almost normal histological architecture of renal parenchyma; preservation of tubular morphology compared to the group treated with KCV group alone was observed; however, mild congestion of the glomerular capillaries and intertubular blood vessels was present (Fig. $3 \mathrm{~g}$ and $\mathrm{h}$ ).

\section{DISCUSSION}

Envenomation by KCV produces profound abnormalities characterized by extensive tissue necrosis and minimal neurotoxic symptoms [16]. The lethal neurotoxin protein (Toxin CM36) venom of the King Cobra produced irreversible blockade of rat phrenic nerve diaphragm [17]. The venom of King Cobra contains 66 KD a metalloproteinase enzyme that binds the receptor GPIIb/GPIIIa on the platelet surface resulting in hemorrhage [18], and the lethal toxic phospholipase A2 (PLA2) which can induce myotoxicity, cardiotoxicity, and antiplatelet effects [9].

The antivenom immunotherapy side effects have been related to the action of high concentrations of non-immunoglobulin proteins available

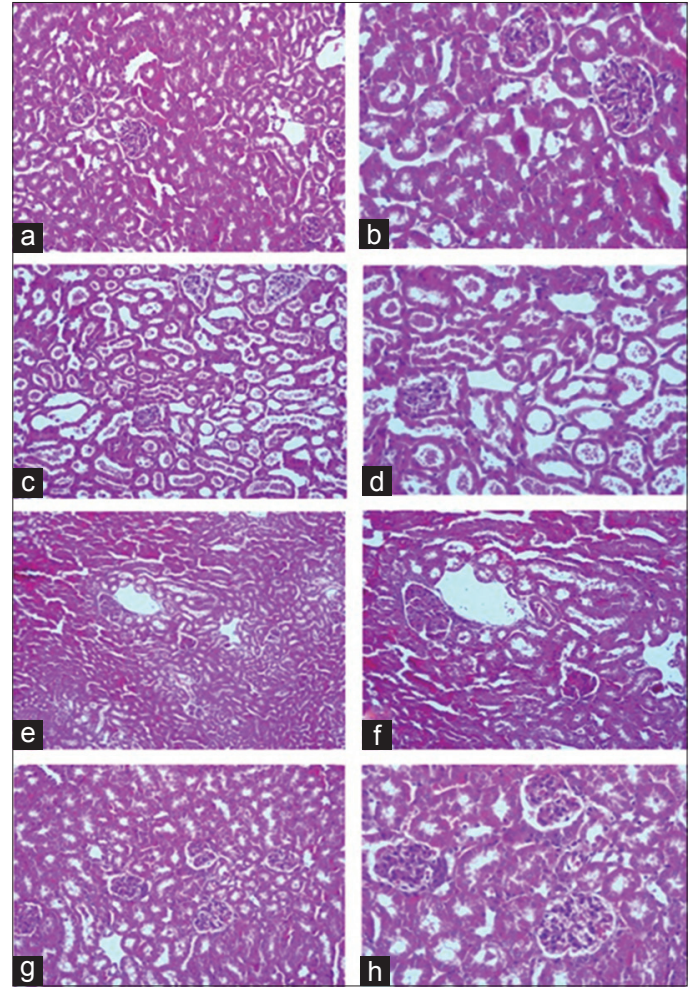

Fig. 3: Photographs of kidney tissue of a control mouse (a and b) showing normal structural appearance of the kidney, (c and d) Group $\mathrm{V}$ is showing degenerative changes in the severe damage in renal tissues. ( $e$ and $f$ ) group TV1 showing mild degeneration of the renal tissues, ( $g$ and $h$ ) group TV2 showing reduction of the intensity of the lesions induced by the KCV. $H$ and E. Original magnification; "a, c, e, g × 20" "b, d, f, h ×40"

as hyperimmune antivenom [19]. Numerous herbal plants that have antivenom activity are used as folk medicine for treatment of snakebite. They have minimal side effects compared with the serum therapy and can counteract snake venom activity [20]. In this regard, the snake venom antagonists of several plants have been investigated, for example, the H. aethiopicus extract herbal solution totally blocked the hemorrhagic activity of the snake Echis ocellatus in the egg embryo [10]. Grape seed methanolic extract abolished the proteolytic activities and neutralized the hemorrhage, edema inducing, and myonecrotic properties of the Indian Vipera russellii venom [21]. Pre-treatment of rats with Mucuna pruriens seed extract deliberated effective protection against lethality of Naja sputatrix venom and moderate protection against Calloselasma rhodostoma venom [22].

Numerous studies described the use of various plants for treating King Cobra bite. A glycoprotein was purified from a folk medicinal plant, Withania somnifera has been found to be effective in Cobra bites, and it inhibited the hyaluronidase activity of Cobra [23]. Antisnake venom drug (AIPLAI) was isolated from leaves of Azadirachta indica that is significantly inhibiting the PLA2 enzymes of Cobra and Russell's viper venoms [24]. In the present investigation, we applied one of the main traditional herbal plants, tamarind which is used as folk medicine for the treatment of many clinical complications and snake envenomation $[13,14]$. The anti-snake venom properties of the tamarind has been studied by many authors, the tamarind seed coat extract neutralizes the lethal action of the Russell's viper venom and inhibits the action of its major enzymes which are responsible for local tissue damage, inflammation, and hypotension, it also neutralized the degradation of the $\mathrm{B} \beta$ chain of human fibrinogen and the edema, hemorrhage, and myotoxic effects including lethality, induced by venom $[15,25]$. 
In the present study, serious tissue damage was detected in the skeletal muscle, liver, and kidney of mice injected with KCV solution. Mild-to-severe myonecrosis associated with congested blood vessels and inflammatory cells was evident in the thigh muscle 1 day after the venom injection; treatment with low dose of TSE solution showed mild myonecrosis while higher dose revealed undamaged fibers. These observations of TSE effect on muscle histological damage induced by $\mathrm{KCV}$ are similar to the effect of Anacardium occidentale bark extract on the myonecrosis induced by Vipera russelii venom [25], and to the grapes seed methanolic extract on the myonecrotic properties of the V. russellii venom [21]

Histological examination of liver sections taken from envenomated mice demonstrated distorted liver architecture associated with congested central veins and mononuclear cellular infiltration. Administration of low dose of tamarind extract caused partial improvement in the histological structure of the liver showing minimal degenerative changes in the hepatocytes and blood sinusoids. The improvement is increased with the dose, showing normal hepatic cords, hepatocytes, and central veins. Sections of a kidney from envenomated mice showed intense abnormalities including signs of glomerular degeneration, tubular necrosis, the formation of hyaline, and tubular casts and intertubular hemorrhage. A low dose of tamarind extract showed no improvement in the histopathological alteration induces by KCV; while high dose caused partial improvement, there was a reduction of the histological lesions induced by the KCV. The Stenolobium stans (L.) Seem was found to reduce and neutralized the biochemical parameters of cardiac, liver, and renal toxicities induced by Naja naja karachiensis envenomation in rats [26], and the Rhazya strictadecne plant extract improved the histological structure alterations and injuries of the liver and kidney induced by the yellow scorpion Leurius quinquestriatus venom in mice. The histopathological alterations in the skeletal muscles fibers, liver, and kidney obtained from envenomed mice with KCV demonstrated in this study may be attributed to the toxic effect of one or more of the active pharmacological compounds of the Cobra venom such as hospholipase A2 (PLA2) or 63-66 KDa metalloproteinase enzymes. The venom from Elapidae family snakes possesses a multitude of toxins with different toxic or enzymatic properties; mainly neurotoxins, causing paralysis of muscle, and death by respiratory failure $[27,28]$

Several mechanisms of snake venom neutralization by medicinal plants such as protein precipitation, enzyme activation, chelation, adjuvant action, antioxidant, protein folding, and much more have been suggested by Makhija and Khamar [29]. The medicinal plants can increase snakebite victim survival time, decrease the severity of toxic signs, enhance diaphragm muscle contraction, block antibody attachment to venom, and inhibit protein destruction [30]. The role of tamarind plant in reducing the toxicity induced by the venom in this study may be attributed to its antioxidant activity [31], demonstrating that tamarind pulp and seed extracts possess beneficial antioxidant properties. The natural antioxidants could act as membrane stabilizers by maintaining the sulfhydryl groups of membrane proteins and preventing cell injury by quenching free radicals [32]. Antioxidants can protect against the damage induced by free radicals by maintaining the glutathione content that reacts with free radicals and terminates lipid peroxidation thereby preventing tissue damage [33]. Further, ultrastructural and biochemical investigations are needed to explore the active ingredients as well as the mechanisms of the neutralization or inhibition action of the TSE in the muscle, liver, and kidney against snake envenomation.

\section{CONCLUSION}

The present study demonstrated that TSE reduced the histopathological changes in the muscle, liver, and kidney induced by KCV in mice. Thus, the extract possesses anti-snake venom property and may have a potential therapeutic agent for envenomation by snake venom

\section{ACKNOWLEDGMENT}

This study was supported by International Islamic University Malaysia (RIGS 16-286-0450). The authors are thankful to Br Ramali, Pengarah, Jabatan Landscape, for a donation of King Cobra snake venom.

\section{REFERENCES}

1. Gutiérrez JM, Escalante T, Rucavado A, Herrera C. Hemorrhage caused by snake venom metalloproteinases: A journey of discovery and understanding. Toxins (Basel) 2016;8(4):93.

2. Janardhan B, Shrikanth VM, Dhananjaya BL, More SS. Antisnake venom properties of medicinal plants. Int $\mathrm{J}$ Pharm Pharm Sci 2014;7(S1):21-6

3. Nisha NC, Sreekumar S, Biju CK. Identification of lead compounds with cobra venom detoxification activity in Andrographis paniculata (Burm. f.) Nees through in silico method. Int J Pharm Pharm Sci 2016;8(7):212-7.

4. Calil-Elias S, Thattassery E, Martinez AM, Melo PA. Effect of perimuscular injection of Bothrops jararacussu venom on plasma creatine kinase levels in mice: Influence of dose and volume. Braz J Med Biol Res 2002;35(10):1233-5.

5. Harris JB, Scott-Davey T. Secreted phospholipases A2 of snake venoms: Effects on the peripheral neuromuscular system with comments on the role of phospholipases A2 in disorders of the CNS and their uses in industry. Toxins (Basel) 2013;5(12):2533-71.

6. Al-Sadoon MK, Orabi GM, Badr G. Toxic effects of crude venom of a desert cobra, Walterinnesia aegyptia, on liver, abdominal muscles and brain of male albino rats. Pak J Zool 2013;45(5):1359-66.

7. Ghani LM, El-Asmer MF, Abbas OA, Rahmy TR. Histological and immunohistochemical studies on the nephrotoxic effects of Naja nigricollis snake venom. Egypt J Nat Toxins 2010;7(2):29-52.

8. Al-Johany AM, Al-Sadoon MK, Abdel Moneim AE, Bauomy AA, Diab MS. Histological, molecular and biochemical detection of renal injury after Echis pyramidum snake envenomation in rats. Saudi J Biol Sci 2015;22(3):302-11.

9. Veto T, Price R, Silsby JF, Carter JA. Treatment of the first known case of king cobra envenomation in the United Kingdom, complicated by severe anaphylaxis. Anaesthesia 2007;62(1):75-8.

10. Georgieva DN, Rypniewski W, Perbandt M, Jain M, Genov N, Betzel C. Crystallization and preliminary X-ray diffraction studies of a toxic phospholipase A2 from the venom of Vipera ammodytes meridionalis complexed to a synthetic inhibitor. Biochim Biophys Acta 2003; 1650(1-2):1-3

11. Hasson SS, Al-Jabri AA, Sallam TA, Al-Balushi MS, Mothana RA. Antisnake venom activity of Hibiscus aethiopicus L. Against Echis ocellatus and Naja n. Nigricollis. J Toxicol 2010;2010:837864.

12. Rathnasamy S, Mohamed KB, Sulaiman SF, Akinboro A. Evaluation of cytotoxic, mutagenic and antimutagenic potential of leaf extracts of three medicinal plants using Allium cepa chromosome assay. Int Curr Pharm J 2013;2(8):131-40.

13. Bandawane D, Mayuri H, Ashish M, Nilam M. Evaluation of antiinflammatory and analgesic activity of tamarind (Tamarindus Indica L.) Seeds. Int J Pharm Pharm Sci 2013;5:623-9.

14. Rasheed S. Antibacterial activity of Tamarindus indica seeds extract and study of the effect of extract on adherence and biofilm production of some bacteria. Int J Biol Pharm Res 2014;5(1):42-7.

15. Maung KM, Lynn Z. Effects of tamarind (Tamarindus indicus Linn) seed extract on Russell's viper (Daboia russelli siamensis) venom. Trop Biomed 2012;29(4):580-7.

16. Kakaria A, Agarwal S, Bagul J. A study of cobra envenomation: Clinical features and management. Management 2014;3(54):20.

17. De P, Dasgupta SC, Gomes A. A lethal neurotoxic protein from Indian king cobra (Ophiophagus hannah) venom. Indian J Exp Biol 2002;40(12):1359-64.

18. Chen RQ, Jin Y, Wu JB, Zhou XD, Lu QM, Wang WY, et al. A new protein structure of P-II class snake venom metalloproteinases: It comprises metalloproteinase and disintegrin domains. Biochem Biophys Res Commun 2003;310(1):182-7.

19. Devi CM, Bai MV, Lal AV, Umashankar PR, Krishnan LK. An improved method for isolation of anti-viper venom antibodies from chicken egg yolk. J Biochem Biophys Methods 2002;51(2):129-38.

20. Gomes A, Das R, Sarkhel S, Mishra R, Mukherjee S, Bhattacharya S, et al. Herbs and herbal constituents active against snake bite. Indian $\mathrm{J}$ Exp Biol 2010;48(9):865-78.

21. Mahadeswaraswamy YH, Devaraja S, Kumar MS, Goutham YN, Kemparaju K. Inhibition of local effects of Indian Daboia/Vipera 
russelli venom by the methanolic extract of grape (Vitis vinifera $\mathrm{L}$.) Seeds. Indian J Biochem Biophys 2009;46(2):154-60.

22. Tan NH, Fung SY, Sim SM, Marinello E, Guerranti R, Aguiyi JC. The protective effect of Mucuna pruriens seeds against snake venom poisoning. J Ethnopharmacol 2009;123(2):356-8.

23. Machiah DK, Girish KS, Gowda TV. A glycoprotein from a folk medicinal plant, Withania somnifera, inhibits hyaluronidase activity of snake venoms. Comp Biochem Physiol C Toxicol Pharmacol 2006;143(2):158-61.

24. Mukherjee AK, Doley R, Saikia D. Isolation of a snake venom phospholipase A2 (PLA2) inhibitor (AIPLAI) from leaves of Azadirachta indica (Neem): Mechanism of PLA2 inhibition by AIPLAI in vitro condition. Toxicon 2008;51(8):1548-53.

25. Ushanandini $S$, Nagaraju $S$, Harish Kumar $K$, Vedavathi $M$, Machiah DK, Kemparaju K, et al. The anti-snake venom properties of Tamarindus indica (leguminosae) seed extract. Phytother Res 2006;20(10):851-8.

26. Asad MH, Murtaza G, Ubaid M, Durr-e-Sabih, Sajjad A, Mehmood R, et al. Naja naja karachiensis envenomation: Biochemical parameters for cardiac, liver, and renal damage along with their neutralization by medicinal plants. Biomed Res Int 2014;2014:970540.
27. Birrell GW, Earl ST, Wallis TP, Masci PP, de Jersey J, Gorman JJ, et al. The diversity of bioactive proteins in Australian snake venoms. Mol Cell Proteomics 2007;6(6):973-86.

28. Kulkeaw K, Chaicumpa W, Sakolvaree Y, Tongtawe P, Tapchaisri P. Proteome and immunome of the venom of the Thai cobra, Naja kaouthia. Toxicon 2007;49(7):1026-41.

29. Makhija IK, Khamar D. Anti-snake venom properties of medicinal plants. Pharm Lett 2010;2(5):399-411.

30. Shabbir A, Shahzad M, Masci P, Gobe GC. Protective activity of medicinal plants and their isolated compounds against the toxic effects from the venom of Naja (cobra) species. J Ethnopharmacol 2014;157:222-7.

31. Khairunnuur FA Jr, Zulkhairi A, Azrina A, Moklas MM, Khairullizam S, Zamree MS, et al. Nutritional composition, in vitro antioxidant activity and Artemia salina L. Lethality of pulp and seed of Tamarindus indica L. Extracts. Malays J Nutr 2009;15(1):65-75.

32. Barnes J, Anderson LA, Phillipson JD. Herbal Medicines: A Guide for Healthcare Professionals. $2^{\text {nd }}$ ed. London: Pharmaceutical Press; 2002.

33. Nabil Z, Hussein A, Moustafa A, Ahmed S, Omran M. Assessment of the therapeutic effect of Calotropis procera extract compared to digoxin on myocardial pathology: An experimental study. Egypt J Nat Toxins 2006;3:51-76. 